\title{
COMPOSIÇÃO QUÍMICA DE RESÍDUOS AGROINDUSTRIAIS COM USO POTENCIAL NA BIOTECNOLOGIA
}

\author{
Natalia Anniboleti Santos ${ }^{1}$, Ayrton Gibrail Kury Lins de Melo ${ }^{1}$; José Rulio Ferreira Silva ${ }^{1}$; \\ Mariana Santos Moreira ${ }^{1}$; Patrícia dos Santos Souza ${ }^{1}$; Yone Silva ${ }^{1}$; Kelly Alencar Silva ${ }^{1}$ \\ (kelly.silva@uva.br) \\ ${ }^{1}$ Departamento de Nutrição, Universidade Veiga de Almeida, RJ.
}

O Brasil tem grande potencial na área biotecnológica por ser gerador de resíduos agroindustriais. Dentre os resíduos produzidos estão: soro lácteo (subproduto da indústria de laticínios), leitelho (obtido do processamento de manteiga), milhocina (subproduto de beneficiamento do milho) e tegumento da manga (camada mais externa do caroço). Esse trabalho identificou a composição centesimal dos resíduos citados que podem ser utilizados em estudos biotecnológicos. Empresas nacionais doaram as amostras que foram analisadas no Laboratório de Bromatologia da Universidade Veiga de Almeida - RJ. Avaliou-se teores de umidade, resíduo mineral fixo (RMF), lipídio total, proteína e carboidrato total em duplicatas, utilizando os métodos indicados pelo Instituto Adolfo Lutz, (2011). A umidade foi determinada por secagem em estufa a $105^{\circ} \mathrm{C}$. O RMF foi pré-incinerado e calcinado em mufla à $550^{\circ} \mathrm{C}$. As frações lipídicas por Bligh Dyer para os resíduos líquidos e por Soxhlet para o tegumento. A proteína pelo método de microKjedahl e o carboidrato total foi calculado por diferença. O resíduo de soro de queijo coalho, apresentou em g\% umidade $(95,23 \pm 0,12)$; RMF $(0,78 \pm 0,11)$; proteína $(0,60 \mathrm{~g} \% \pm 0,25)$; lipídio $(0,41 \pm 0,00)$ e carboidrato $(2,98 \pm 0,00)$. O soro de ricota, umidade $(94,68 \pm 0,05)$; $\operatorname{RMF}(0,47 \pm 0,00)$; proteína $(1,25 \pm 0,77)$; lipídio $(2,77 \pm 0,00)$ e carboidrato $(0,83 \pm 0,00)$. O leitelho valores de umidade $(89,23 \pm 0,63)$; $\operatorname{RMF}(0,64 \pm 0,03)$; proteína $(4,58 \pm 0,36)$; lipídio $(2,78 \pm 0,00)$ e carboidrato total de $(2,91 \pm 0,00)$. Notou-se que dentre os soros lácteos, o soro de manteiga $(4,58 \pm 0,36)$ apresentou maior quantidade de proteína e o soro de queijo coalho e de manteiga de lipídios. Já a milhocina apresentou os seguintes valores: umidade $(49,84 \pm$ 1,00), $\operatorname{RMF}(8,01 \pm 0,04)$; proteína $(18,03 \pm 2,53)$; lipídio $(0,36 \pm 0,00)$ e carboidrato total de $(23,76 \pm$ $0,00)$. Dentre todos os resíduos foi o que apresentou maior valor de proteína total. O tegumento apresentou umidade $(8,97 \pm 0,31), \operatorname{RMF}(1,00 \pm 0,02)$; proteína $(2,67 \pm 0,23)$; lipídio $(0,20 \pm 0,06)$ e carboidrato total $(87,16 \pm 0,00)$. Como o carboidrato foi calculado por diferença, o tegumento apresentou maior teor dentre todos os resíduos justamente por ser um resíduo rico em fibra. Como conclusão, é possível destacar que os resíduos estudados possuem interessante composição centesimal para serem usados como matéria prima, entretanto a composição destes pode ser variável dependendo das condições e qualidade da matéria prima e do processamento.

Palavras-chave: composição centesimal; agroindústria; ciência dos alimentos. 